\title{
Centenarian Offspring: A Model for Understanding Longevity
}

\author{
Carmela Rita Balistreri*, Giuseppina Candore, Giulia Accardi, Silvio Buffa, Matteo Bulati, Adriana Marto- \\ rana, Giuseppina Colonna-Romano, Domenico Lio and Calogero Caruso
}

Department of Pathobiology and Medical and Forensic Biotechnologies, University of Palermo, Palermo, Italy

\begin{abstract}
A main objective of current medical research is to improve the life quality of elderly people as priority of the continuous increase of ageing population. This phenomenon implies several medical, economic and social problems because of dramatic increase in number of non autonomous individuals affected by various pathologies. Accordingly, the research interest is focused on understanding the biological mechanisms involved in determining the positive ageing phenotype, i.e. the centenarian phenotype. In achieving this goal the choice of an appropriate study models is fundamental. Centenarians have been used as an optimal model for successful ageing. However, this model shows several limitations, i.e. the selection of appropriate controls and the use itself of the centenarians as a suitable model for healthy ageing. Thus, the interest has been centered on centenarian offspring, healthy elderly people. They may represent a model for understanding exceptional longevity for the following reasons: they exhibit a protective genetic background, cardiovascular and immunological profile, as well as a reduced rate of cognitive decline than age-matched people without centenarian relatives. Several of these aspects are summarized in this review based on the literature and the results of our studies.
\end{abstract}

Keywords: Ageing, cardiovascular profile, centenarians, centenarian offspring, genetic background, immunosenescence, memory decline.

\section{INTRODUCTION}

Medical research is currently influenced by the massive ageing of the populations in the developed countries. This trend implies a set of medical, economic and social problems, principally caused by the increased number of not autonomous elderly individuals affected by several pathologies. Thus, an improvement of human elderly health is required. This is leading the research interest to focus its attention on the so-called positive biology. It differs from wellknown current biology, which principally researches the causes of the chronic diseases, such as cardiovascular diseases (CVD), cancer and Alzheimer disease (AD), today afflicting millions of people. In contrast, positive biology has a principal goal of identification of the biological mechanisms characterising the positive phenotypes. In this contest, an interesting positive phenotype is given by exceptional individuals living long, showing relatively good health, able to perform their daily life tasks and to escape fatal agerelated diseases $[1,2]$. The investigation of this particular positive phenotype, "phenotype of exceptional longevity", can represent a remarkable study's model of health and wellbeing. This new study's approach might provide useful data, whose translation might have several beneficial effects: from the modulation of ageing rate to the development of drugs or new lifestyle habits (i.e. a healthy diet, caloric uptake reduction, use of antioxidants, prebiotics and probiotics and

\footnotetext{
*Address correspondence to this author at the Researcher of Clinical Pathology, Department of Pathobiology and medical and forensic Biotechnologies (DIBIMEF), University of Palermo, Corso Tukory, 211, 90134 Palermo; Tel: +390916555903; +39347-9394535; Fax: +390916555933; Email: carmelarita.balistreri@unipa.it
}

increased physical exercise) able in enhancing health and well-being, in retarding ageing and preventing or reducing frailty and disability especially in individuals genetically predisposed. Furthermore, this new study approach might provide evidence, which would further strengthen the concepts of ageing theories $[1,2]$.

From this point of view, centenarian offspring (CO), healthy elderly people with a family history of longevity, may represent the most appropriate model for understanding exceptional longevity for several reasons. Firstly, they have a familial trait influenced principally by genetic factors and environmental conditions. Another reason is given by the possibility to obtain more applicable and reasonable findings than those achieved by investigations from laboratory animals, being different as organisms. Apart from differences in their genomes, development and life expectancy, the major difference between humans and laboratory animals is the quantity and quality of antigenic exposure. Typical laboratory organisms are usually housed in artificially clean environments. Thus, they are underexposed to pathogens, or even completely protected from them, except for limited period of time required for experimental reasons. These animals are quite different from those living in the wild exposed to a plethora of different microorganisms, such as bacteria, viruses and parasites. Human beings have an environment, although controlled, not sterile, but rather full of microbes [3]. Some of them are normally hosted on skin and mucosal tissues, having a protective role against pathogenic microbes. In contrast, others are or can become pathogenic and trigger infectious diseases, which constituted a major lifethreatening event throughout the natural history of animal species. Furthermore, lifelong antigenic load and the conse- 
quent inflammation are assumed as the major determinants of human ageing rate and unsuccessful ageing.

Other interesting characteristics, such as a protective genetic background, immunological profile and clinical history, seem to be exhibited by $\mathrm{CO}$, when compared with agematched people without centenarian relatives. Many of these aspects are summarized in this review based on literature data and results of our studies.

\section{FOCUS ON CENTENARIANS OFFSPRING: FAVOR- ABLE CARDIOVASCULAR RISK PROFILE}

Several and comparable epidemiological studies in different populations (Ashkenazi Jews, Americans from New England, Japanese from Okinawa, Icelanders, Mormons, Netherlanders from Leiden) have established that the genetic component has a remarkable role in attaining longevity [4-9]. Siblings and CO, but not their spouses, show an increased odd ratio (OR) between 4- and 17-fold for longevity, when compared with appropriate controls $[4,5]$. This supports the existence of strong genetic determinants for longevity. Furthermore, it also suggests that the favorable modulation not only of ageing processes, but also of disease susceptibility, is strongly inherited in families with exceptional longevity. Thus, it supposes a possible transmission from centenarians to their descendants of the capacity to escape and/or postpone the major age-related diseases. In order to assess this, the interest has been centered on $\mathrm{CO}$. On the other hand, their evaluation bypasses some problems, including the selection of appropriate controls for centenarians, the elimination of the doubts to consider the centenarians as useful model for healthy ageing, since only few studies reported centenarians as healthier or well functioning during most of their lives compared with average populations [10-13].

The first data on $\mathrm{CO}$ have been obtained by the group of Perls and Terry, which analyzed in a cross-sectional study the prevalence of several age-related diseases in $177 \mathrm{CO}$ and 166 age-matched controls, without centenarian parents, enrolled in the nationwide New England Centenarian Study [14]. Like centenarians, $\mathrm{CO}$ had a markedly reduced risk for CVD (56\%; OR 0.44, 95\% CI 0.24-0.80), hypertension (66\%; OR 0.34, 95\% CI 0.21-0.55) and diabetes (59\%; OR $0.41,95 \%$ CI $0.15-1.12$ ), than age-matched controls without centenarian parents. Furthermore, the study reported that $\mathrm{CO}$ showed a significant reduction of $62 \%$ in all mortality causes and a lower risk of $85 \%$ for coronary heart disease-specific mortality [15]. In addition, median ages of onset for coronary heart disease, hypertension, diabetes and stroke were significantly delayed in this cohort by 5.0, 2.0, and 8.5 and 8.5 years, respectively, when compared with age-matched controls [16].

This interesting finding has been subsequently confirmed by same researchers [15] that also observed in $\mathrm{CO}$ a lower risk of $71 \%$ in dying cancer when compared with agematched controls. This led them to suppose that at younger ages (e.g. $<70$ years), CO have a lower risk for cancer than controls. However, they also evidenced that this difference disappears as the birth cohort ages and the possible protective factors remain not clear. Accordingly, Perls and Terry suggested in this study that CO may have likely inherited genetic variations from their long-lived parents able to protect them from multiple mutations, thus resulting in lower cancer-specific mortality [15].

The promising findings of Perls and Terry have been confirmed by a recent longitudinal study executed in a group of $440 \mathrm{CO}$, considered to be predisposed to healthy ageing [4, 14-18], and 192 control subjects, enrolled and followed for over 10 years by the New England Centenarian Study. This longitudinal analysis had a specific goal to discern whether the differences in the susceptibility for age-related diseases between $\mathrm{CO}$ and control subjects persist over time or disappear, as the two groups get older. During the followup period, $\mathrm{CO}$ showed a lower risk of $78 \%$ for myocardial infarction, of $83 \%$ for stroke and of $86 \%$ for diabetes mellitus than the control cohort. No significant differences were observed in onset for other age-related diseases. Additionally, during the follow-up, the $\mathrm{CO}$ showed a reduced mortality equal to $81 \%$ than the controls. Thus the authors suggested that $\mathrm{CO}$ retain some important cardiovascular advantages over time similarly to their parents. In addition, they underlined the concept of longevity family history likely determined by physiological causes, since $\mathrm{CO}$ have a better cardiovascular health and a lower mortality than their peers [17].

Concordant results have been obtained by Barzilai's group. They demonstrated that CO from Ashkenazi Jewish population had a significant lower prevalence for hypertension $(23 \%)$, diabetes mellitus $(50 \%)$, heart attacks $(60 \%)$ and strokes (no events reported) than several age-matched control groups [4].

In this context, it is also noteworthy to mention the data reported by the Long Life Family Study (LLFS) [18], showing in both centenarians and offspring the reduced prevalence for diabetes mellitus, chronic pulmonary disease and peripheral artery disease than those obtained by both Cardiovascular Health Study and Framingham Heart Study cohort members [16]. On the other hand, the LLFS study showed more optimal measures of both physical function and cardiovascular risk factors when compared with the other groups [18].

This data's concordance led indentifying the possible genetic and molecular pathways able to confer the protective cardiovascular profile in CO. Barzilai and colleagues [19, 20] studied the lipid profiles among Ashkenazi Jewish centenarians, their children and thechildren's spouses (the controls in the study). Both male and female children had significantly higher high density lipoprotein-cholesterol (HDLC) levels when compared with controls and the males also had significantly lower low density lipoprotein-cholesterol (LDL-C) levels. In order to focus candidate genes of lipoprotein metabolism, they also identified a higher frequency of a functional variant (homozygosity for the 405 valine) of the gene codifying the cholesteryl ester transfer protein (CETP) in centenarians and their offspring. This genetic variant increases the particle size of both HDL and LDL [21]. Consistent with this, Li and colleagues [22] also reported a larger HDL and LDL protein size in centenarians and their descendants when compared with controls. Newman and colleagues [18] found higher HDL-C levels and lower levels of triglyc- 
erides in LLFS centenarians and CO. These features, identified particularly in $\mathrm{CO}$ reflect their protective lipid and cardiovascular profile. Furthermore, it has been recently evidenced a significant correlation between the genetic CETP variant and a lower prevalence of hypertension, a reduced systolic blood pressure, and a trend toward lower diastolic blood pressure [23].

In a more recent study, Barzilai's group genotyped Ashkenazi Jewish centenarians $(n=213)$, their offspring $(n=$ 216) and an age-matched Ashkenazi control group $(n=258)$ for 66 polymorphisms in 36 genes related to CVD. They observed a higher prevalence of homozygosity for the -641C (rs2542052) allele inthe APOC3 promoter in centenarians (25\%) and their offspring (20\%) than controls (10\%). This genotype is associated with significantly lower serum levels of APOC3 and a favorable pattern of lipoprotein levels and size. A lower prevalence of hypertension and greater insulinsensitivity in the $-641 \mathrm{C}$ homozygotes was found, suggesting a protective effect against CVD and metabolic syndrome. Homozygosis for the APOC3 -641C allele is associated with a favorable lipoprotein profile, cardiovascular health, insulin sensitivity and longevity. These data show that genetic modulation of lipoproteins may be considered a pathway influencing lifespan [24].

In this contest, of interest also are the concordant data on lower levels of 70-kd heat shock protein (Hsp70) observed by three research groups in centenarians and their offspring. Hsp70 is a highly conserved protein having protective and deleterious effects [25-27]. It is involved in the pathophysiology of the major age-related diseases, and particularly in atherosclerosis and its complications. Usually, its expression and release in vascular smooth muscle cells increases under oxidative stress induced by risk factors, such as smoking, hyperlipidemia, diabetes and hypertension. Thus, circulating Hsp70 levels predict the CVD development. In contrast, in the individuals achieving an advanced age, Hsp70 shows serum lower levels, conferring a beneficial and protective effect. In researching to explain the differences in serum Hsp70 levels between centenarians, their offspring and agematched controls from the New England Centenarian Study and the Longevity Genes Project on Ashkenazi Jewish population, they were genotyped for two functional tag polymorphisms, rs1043618 in HSP70-A1A and rs6457452 in HSP70A1B genes. The data obtained demonstrated no associations. However, serum Hsp70 levels may be considered as biomarkers of exceptional longevity [28].

Another possible and key pathway is that of insulin/IGFI. In 2007, Cohen and colleagues studied the level of IGFI in Ashkenazi Jewish descendants. They showed higher levels of this factor related to the control population without a family history of longevity. In particular, they found higher serum levels of $35 \%$ in female $\mathrm{CO}$ respect to age and gendermatched controls. In contrast, male offspring showed the same levels as controls [29].

These results suggest that phenotypic and genotypic characteristics associated with exceptional longevity are transmitted in long lived families. In addition, they emphasize the importance of cardiovascular health in achieving exceptional old age as well as the familial nature of longevity.

\section{REDUCED RISK FOR ALZHEIMER'S DISEASE AND MEMORY DECLINE IN CENTENARIAN OFF- SPRING}

With advancing age, individuals can experience cognitive decline and develop several forms of dementia. Among these, $\mathrm{AD}$ represents one of the major health problems, afflicting millions of people today [30]. Centenarians are escaping and/or postponing this pathology [4, 21,31]. No consistent data exist on the eventual advantage transmitted from centenarians to their offspring to maintain a high physical and cognitive function and sustained engagement in social and productive activities, and to outlive this disease. Longitudinal studies in $\mathrm{CO}$ and offspring of parents with the average of life expectancy at birth for specific cohorts, using rigorous neuropsychological assessments are needed to clarify the influence of parental longevity on cognitive decline.

Recently, the Bronx Aging Study [32] provided the opportunity to apply this approach. The study enrolled community residing subjects (aged 75-85 years) from 1980 to 1983 and it followed them for 23 years. The study included information on parental age at death and extensive annual clinical, neuropsychological and neurological evaluations to determine memory decline and the incidence of dementia during follow-up. Using the data from the Bronx Aging Study, the Barzilai group tested the hypothesis that parental longevity protects against memory decline and the onset of dementia. Indeed, they demonstrated that $\mathrm{CO}$ had a reduced incidence for $\mathrm{AD}$ (hazard ratio0.57; 95\% CI: $0.35-0.93$ ) than the control group. In particular, they showed a reduced prevalence to develop dementia equal to $36 \%$ than the control group. They also had a significantly reduced rate of memory decline on the Selective Reminding Test when compared with the control group [32].

On the other hand, Barraland colleagues [33] observed in CO generation from LLFS family members, a better performance on multiple tasks requiring attention, working memory and semantic processing when compared with individuals without a family history of exceptional survival. This suggests that cognitive performance may serve as an important endophenotype for longevity [33]. Hagberg and Samuelsson [34] also evidenced that hereditary factors, social relationships, marital status and personality did not contribute to survival prediction in this exceptional age group. In consequence, in very old age, stochastic determinants may dominate over programmed factors (for example family longevity) in the determining of survival. Yates and colleagues [35] found in individuals with more of 90 years a better latelife physical function (mean \pm SD score [maximum 100], 73 \pm 23 vs $62 \pm 30, \mathrm{p}<0.001$ ) and mental well-being (mean score, $84 \pm 14$ vs $81 \pm 17, \mathrm{p}=0.03$ ).

Based on these observations, $\mathrm{CO}$ develops dementia and $\mathrm{AD}$ at a significantly higher age than controls. This result is not explained by demographic or medical confounders. Factors associated with longevity may protect against dementia and $\mathrm{AD}$. 


\section{IMMUNOLOGICAL HALLMARKS IN CENTENAR-} IAN OFFSPRING

The age-related decline of the immune system, which accompanies the ageing with several modifications, is called immunesenescence [36- 38]. A reduced amount of T, B and NK cells is observed in healthy elderly people [39-43]. Furthermore, the $\mathrm{T}$ cell compartment shows shrinkage in elderly people of a cellular repertoire caused by the filling of the immunological space characterized by memory-late differentiated (CD3+CD8+CD45RA-CD27-CD28-) CD8+ T cells [44]. Concerning the B cellular compartment, studies did not lead to a common consensus. Several contrasting data have been suggested on changes occurring in the naive/memory subsets. However, a serum increase of switched immunoglobulins and a reciprocal decrease of both serum $\operatorname{IgM}$ and IgD have been demonstrated in elderly people [45-47]. This last evidence seems to be in agreement with the reduced number of naive $B$ cells and the increase of a Double negative, $\mathrm{DN}\left(\mathrm{IgD}^{-} \mathrm{CD} 27^{-}\right) \mathrm{IgG}^{+} \mathrm{B}$ cell population, observed in healthy elderly, as reported by our recent studies [43, 49, 50].

The interest in establishing the relevance of the immunological features in the centenarian phenotype also led to detect several immune parameters [47, 50-54]. Therefore, it has been suggested that centenarians share some typical immunological parameters of young people and others characteristic of the elderly. Among these, the number of NK cells and their activity in centenarians are well conserved and comparable to those observed in young people, when compared with elderly people. In contrast, a decrease in B lymphocytes and naive T cells, a progressive increase of CD28cytotoxic $\mathrm{T}$ cells, the expansion of clones of memory $\mathrm{T}$ cells, a shrinkage of the $\mathrm{T}$ cell repertoire characterise the centenarians, are typical changes of immunosenescence. Furthermore, they have no organ-specific auto-antibodies, often observed in healthy elderly individuals, and they present some signs of inflammation, including high plasma levels of pro-inflammatory cytokines, i.e. IL-6 and a lipoprotein, Lp(a), considered a CVD risk factor and genetically controlled, as well as coagulation factors [36, 37, 52, 55-57].

Siblings and offspring of long lived subjects, as described above, also represent a good model to analyse the immune profile and consequently to understand the advantages of centenarian phenotype [25, 58-60]. Until now, the literature has reported only on some aspects of the $\mathrm{CO}$ immune profile, i.e. data about the $\mathrm{B}$ cell branch. In this context, our recent data are of interest. Comparing the B cells from individuals of different age groups (young, elderly and $\mathrm{CO}$ ), we noted that $\mathrm{B}$ cells from $\mathrm{CO}$ are more comparable to those from young people, when compared with those from healthy old subjects. Like young individuals, $\mathrm{CO}$ is characterised, indeed, by an increase of naïve $\left(\operatorname{IgD}^{+} \mathrm{CD} 27^{-}\right) \mathrm{B}$ cells [61]. This is a remarkable observation, since the bone marrow ability to generate B cells is impaired with age [61]. Furthermore, our comparative analysis revealed that $\mathrm{CO}$ also has a decrease in percentage of DN B cells [43]. The analysis of serum IgM concentration in $\mathrm{CO}$ also revealed the presence of higher levels in CO than their controls. Our supposition is that $\mathrm{CO}$ behaves as the young individuals. This might allow them to preserve themselves from new infections and to respond to vaccinations. All together, these data might be related to their healthier ageing [62].

\section{ROLE OF VARIATIONS IN HUMAN TELOMERASE GENE AND MITOCONDRIAL DNA}

A close relation between telomere length and life span in humans, including long lived humans, has been reported [63]. However, interpretations of results are often confounded because of a lack of adequate controls [64, 65]. Recently, the group of Barzilai employed an unique study design to overcome this inadequacy in a cohort of Ashkenazi Jewish individuals with exceptional longevity (centenarians), their offspring (approximate age of 70 years), and age- and gender-matched controls without a family history of longevity. Using this study's approach, the potential associations between telomere length and longevity, and age-related diseases have been investigated. Furthermore, the potential role of genetic variations in human telomerase reverse transcriptase (hTERT) and human telomerase RNA component (hTERC) genes in the better maintenance of telomere length in the centenarians and their $\mathrm{CO}$ has been also assessed [66].

The Barzilai's group demonstrated significantly longer telomeres in centenarians and their offspring than the controls [66]. In addition, $\mathrm{CO}$ did not show an appreciable agerelated decline in telomere length as observed using unrelated controls or in cross-sectional studies [66].

Because shorter telomere length is associated with agerelated disease, including hypertension, metabolic syndrome and dementia, the authors also analyzed the association between telomere length, the major age-related diseases and lipid profiles in centenarians, their offspring and controls $[64,65,67]$. They observed that longer telomeres are indeed associated with lower prevalence of hypertension, metabolic syndrome, type 2 diabetes mellitus and a better cognitive function, as well as with healthier lipid profiles. In addition, they reported that two synonymous $(973 \mathrm{G}>\mathrm{A}$ (Ala-305 Ala) and $3097 \mathrm{C}>\mathrm{T}$ (His-1013 His)) and two intronic variants (IVS1-187 T > C andIVS16+99 C > T) and their haplotypes in hTERT gene are enriched in centenarians when compared with controls. These variants are known to play a functional role in the regulation of gene expression through modulation of mRNA stability, mRNA secondary structure, alternative splicing or translational efficiency [66]. Thus, the telomerase genes may function as important genetic determinants of both human longevity and telomere length. Additionally, these data suggest that both telomere length and variants of telomerase genes may have a cumulative influence on lower disease prevalence and a favorable lipid profile in centenarians and their offspring [66, 67].

Mitochondrial DNA (mtDNA) is another important tool to understand longevity [68]. It encodes for 2rRNA, 22 tRNA and 13 polypeptides that take part to oxidative phosphorylation process [69]. It produces reactive oxygen species potentially dangerous for the mitochondrion itself [69]. It does not present non coding region except one, the Dloop, containing binding sites for the replication and transcription [69]. Iwata and colleagues [69] published a paper about mtDNAmutations in Askhenazi Jews. In particular, blood leukocyte samples of mixed gender offspring and non-maternally related controls were analyzed to confirm 
Table 1. Molecular and phenotypical features of $\mathrm{CO}$.

\begin{tabular}{|c|c|c|}
\hline Lipid and Cardiovascular Profile & Changes & References \\
\hline Serum level of APOC3 & Decrease & {$[24]$} \\
\hline Serum level HSP70 & Decrease & {$[25-28]$} \\
\hline Level and larger size LDL-C & Decrease & [18-22] \\
\hline Level and larger size HDL-C & Increased & [18-22] \\
\hline Risk for hypertension & Decrease & {$[4,14-18]$} \\
\hline Risk for type II diabetes & Decrease & {$[4,14-18]$} \\
\hline Risk of stroke & Decrease & {$[4,14-18]$} \\
\hline Risk myocardial infarction & Decrease & {$[4,14-18]$} \\
\hline Coronary heart disease & Decrease & {$[4,14-18]$} \\
\hline Cognitive Profile & Changes & References \\
\hline Development of dementia & Reduced & {$[21,32-35]$} \\
\hline Development of Alzheimer's disease & Reduced & {$[4,21]$} \\
\hline Favorable Immunological Profile & Changes & References \\
\hline Naïve $\mathrm{T}$ cells $\left(\mathrm{CD}^{+}{ }^{+} \mathrm{CD} 8^{+} \mathrm{CD} 45 \mathrm{RA}^{+} \mathrm{CCR} 7^{+} \mathrm{CD} 27^{+} \mathrm{CD} 28^{+}\right)$ & Increase & [43] \\
\hline Late differentiated effector memory $\mathrm{T}$ cells $\left(\mathrm{CD} 3^{+} \mathrm{CD} 8^{+} \mathrm{CD} 45 \mathrm{RA}^{-} \mathrm{CCR} 7^{-} \mathrm{CD} 27^{-} \mathrm{CD} 28^{-}\right)$ & Decrease & [43] \\
\hline TEMRA $\left(\mathrm{CD}^{+}{ }^{+} \mathrm{CD} 8^{+} \mathrm{CD} 45 \mathrm{RA}^{+} \mathrm{CCR} 7^{-\mathrm{CD}} 27^{-} \mathrm{CD} 28^{-}\right)$ & Decrease & [43] \\
\hline Naïve B cells $\left(\operatorname{IgD}{ }^{+} \mathrm{CD} 27^{-}\right)$ & Increase & [44] \\
\hline Double Negative B cells $\left(\operatorname{IgG}^{+} / \operatorname{Ig} A^{+} \operatorname{IgD} C^{-} 2^{2} 7^{-}\right)$ & Decrease & [44] \\
\hline Serum IgM & Increase & {$[44]$} \\
\hline Genetic Profile & Changes & References \\
\hline Homozygosis for the $-641 \mathrm{C}$ (rs 2542052 ) allele inthe APOC3 promoter & Increase & [24] \\
\hline Homozygosis for the 405 valine of CEPT & Increase & {$[19-21,23]$} \\
\hline Telomere attrition & Decrease & {$[66]$} \\
\hline Presence of synonymous andintronic variants in h-TERT gene & Increase & {$[66]$} \\
\hline Heteroplasmic $\mathrm{T} 152 \mathrm{C}$ variant in mt-DNA & Increase & [69] \\
\hline
\end{tabular}

the role of the C150T transition in longevity. This variant occurs in one of heavy chain replication origins shifting this origin from position 151 to 149. The Iwata's group observed that this genetic variant is more frequently expressed in Italian centenarians [69]. No association of this variant with longevity has been confirmed in Askhenazi population [69]. Thus, these data suggest that this genetic variant is population-dependent, as shown in some populations, including Finnish and Japanese populations [69]. In contrast, an ageing-related raise of the heteroplasmic T152C transition frequency has been observed. However, other studies will be useful to confirm the role of these mutations in longevity [69].

\section{CONCLUSION}

In these last years, the gerontologists have focused their efforts in identifying a correct study model to understand the characteristics of successful ageing. $\mathrm{CO}$ seems to represent the appropriate model to analyze successful ageing. They show a favorable lipid, immunological and cardiovascular profile, a decreased cognitive decline and a protective genetic background (Table $\mathbf{1}$ ).

Lower serum levels of APOC3, Hsp70 and LDL-C, and higher amount of HDL-C characterize their lipid and cardiovascular profile [18-22, 24-28]. Cardiovascular health consents them to escape morbidity and mortality for adverse 
cardiac events, including atherothrombosis, myocardial infarction, stroke and heart failure. The CVDs represent the first cause of death in Western countries. This condition implies serious social, medical and economic problems, as hospitalization and assistance of not autonomous and invalid individuals, and the existence of no appropriate therapies.

Furthermore, CO seems to show an optimal immune control. They, like their parents, present a immunological profile which is comparable for several aspects, i.e. number and activity of NK cells and B compartment, to that of young individuals [43, 44]. Thus, $\mathrm{CO}$ behaves as the young people, counteracting new infections and responding to vaccinations. At the same time, this condition determines an adequate control of inflammatory response, and as consequence a concomitant reduction of the risk for the major age-related diseases.

In addition, $\mathrm{CO}$ maintain a high physical and cognitive function, and a sustained engagement in social and productive activities, and they outlive several dementia forms, such as $\mathrm{AD}[4,21,32-35]$.

Another feature of $\mathrm{CO}$ is to have an advantageous genetic background characterized by homozygosity for the $-641 \mathrm{C}$ (rs2542052) allele inthe APOC3 promoter, homozygosity for the 405 valine of CEPT, reduced telomere attrition associated with the presence of synonymous andintronic variants in h-TERT gene, and heteroplasmic T152C variant in mt-DNA [19-21, 23, 24, 66, 69].

The concomitant action of all factors described suggests that the positive ageing phenotype might be the result of an efficient physical performance, rather than an avoidance of death. This allows them to have a major chance to extend survival in health and well-being.

However, other studies are needed to confirm and extend these current data. For example, genomic, transcriptomic and epigenetic investigations may eventually lead to better understanding the molecular and cellular mechanisms associated with successful ageing. On the other hand, the first epigenetic data obtained by the group of Gentilini seem to be promising [70]. They recently demonstrated that a better preservation of DNA methylation status, a slower cell growing/metabolism, and a better control in signal transmission through epigenetic mechanisms may be involved in the process of human longevity [70].

In this future and perspective way of research, it could also be interesting to evaluate the protective role of TERT on mitochondria. It has been recently evidenced that mitochondrial TERT protects mitochondrial DNA and function from damage $[71,72]$. This relatively new research area could be crucial to better understand the cross talk between nucleus and mitochondria and its age-related changes, including the possible impact on successful ageing.

Furthermore, these investigations might also consent likely to understand the biologic gender effect on longevity. A characteristic enigma of longevity is, indeed, the gender and the social phenomenon of "feminization of old age". The demographic and social changes of the past decades, responsible for longevity and the improvements in public health, have created new and often very dissimilar realties for women and men. They differ not only in their anatomy and physiology, but also in more complex traits, such as lifespan (in Italy, 78.8 years for men and 84.1 years for women, respectively) and mortality [73]. No conclusive explanation for these new differences is actually demonstrated. However, the group of Gentilini has recently investigated the role of agerelated $\mathrm{X}$ chromosome inactivation (XCI) skewing in the lifespan of women. The data obtained showed that agedependent skewing of XCI appears delayed in centenarians' offspring [74].

These study approach might permit the identification of targets to use as possible successful ageing biomarkers. Furthermore, it might consent to develop anti-ageing therapies, modulating ageing rate, developing drugs (i.e. antioxidants) or new lifestyle habits (i.e. a healthy diet, caloric uptake reduction, use of prebiotics and probiotics and increased physical exercise).

\section{CONFLICT OF INTEREST}

The authors confirm that this article content has no conflict of interest.

\section{ACKNOWLEDGEMENTS}

This work was supported by grants from the Ministry of Education, University and Research ex $60 \%$ to $\mathrm{CC}, \mathrm{GC}$, CRB and GCR.

\section{LIST OF ABBREVIATIONS}

$\begin{array}{ll}\text { AD } & =\text { Alzheimer disease } \\ \text { APOC3 } & \text { Apolipoprotein C-III } \\ \text { CVD } & =\text { Cardiovascular diseases } \\ \text { CO } & =\text { Centenarian offspring } \\ \text { CETP } & =\text { Cholesteryl ester transfer protein } \\ \text { DN } & =\text { Double negative } \\ \text { Hsp70 } & \text { Heat shock protein } \\ \text { HDL-C } & =\text { High density Lipoprotein-cholesterol } \\ \text { IFG1 } & =\text { Insulin-like growth factor 1 } \\ \text { Lp(a) } & =\text { Lipoprotein } \\ \text { LLFS } & =\text { Long Life Family Study } \\ \text { LDL-C } & =\text { Low density lipoprotein-cholesterol }\end{array}$

\section{REFERENCES}

[1] Farrelly C. 'Positive biology' as a new paradigm for the medical sciences. Focusing on people who live long, happy, healthy lives might hold the key to improving human well-being. EMBO Rep 2012; 13:186-8.

[2] Caruso C, Passarino G, Puca A, Scapagnini G. "Positive biology": the centenarian lesson. Immun Ageing 2012; 9:5. [Epub ahead of print].

[3] O'Hara AM, Shanahan F. The gut flora as a forgotten organ EMBO Rep 2006; 7: 688-93.

[4] Atzmon G, Schechter C, Greiner W, Davidson D, Rennert G, Barzilai N. Clinical phenotype of families with longevity. J Am Geriatr Soc 2004; 52: 274-7.

[5] Perls TT, Bubrick E, Wager CG, Vijg J, Kruglyak L. Siblings of centenarians live longer. Lancet 1998; 351:1560. 
[6] Shimizu K, Takeda S, Noji H, et al. Dietary patterns and further survival in Japanese centenarians. J Nutr Sci Vitam (Tokyo) 2003; 49: 133-38.

[7] Schoenmaker M, de Craen AJ, de Meijer PH, et al. Evidence of genetic enrichment for exceptional survival using a family approach: the Leiden Longevity Study. Eur J Hum Genet 2006; 14: 79-84.

[8] Palsdottir A, Helgason A, Palsson S, et al. A drastic reduction in the life span of cystatin C L68Q carriers due to life-style changes during the last two centuries. PLoS Genet 2008; 4:e1000099.

[9] Carmelli D, Andersen S. A longevity study of twins in the Mormon genealogy. Prog Clin Biol Res 1981; 69A: 81-3.

[10] Darviri C, Demakakos P, Tigani X, et al. Psychosocial dimensions of exceptional longevity: a qualitative exploration of centenarians' experiences, personality, and life strategies. Int J Aging Hum Dev 2009; 69: 101-18.

[11] Hitt R, Young-Xu Y, Silver M, Perls T. Centenarians: the older you get, the healthier you have been. Lancet 1999; 354:652

[12] Samuelsson SM, Alfredson BB, Hagberg B, et al. The Swedish Centenarian Study: a multidisciplinary study of five consecutive cohorts at the age of 100. Int J Aging Hum Dev 1997; 45: 223-53.

[13] Willcox DC, Willcox BJ, Shimajiri S, Kurechi S, Suzuki M. Ageing gracefully: a retrospective analysis of functional status in Okinawan centenarians. Am J Geriatr Psychiatry 2007; 15: 252-5.

[14] Terry DF, Wilcox M, McCormick MA, Lawler E, Perls TT. Cardiovascular advantages among the offspring of centenarians. J Gerontol A Biol Sci Med Sci 2003; 58: M425-31.

[15] Terry DF, Wilcox MA, McCormick MA, Perls TT. Cardiovascular disease delay in centenarian offspring. J Gerontol A Biol Sci Med Sci 2004; 59: 385-9.

[16] Terry DF, Wilcox MA, McCormick MA, et al. Lower all-cause, cardiovascular, and cancer mortality in centenarians' offspring. J Am GeriatrSoc 2004; 52: 2074-6.

[17] Adams ER, Nolan VG, Andersen SL, Perls TT, Terry DF. Centenarian offspring: start healthier and stay healthier. J Am Geriatr Soc 2008; 56: 2089-92.

[18] Newman A, Glynn N, Taylor C, et al. Health and function of participants in the Long Life Family Study: a comparison with other cohorts. Ageing (Albany NY) 2011; 3: 63-76.

[19] Barzilai N, Atzmon G, Schechter C, et al. Unique lipoprotein phenotype and genotype associated with exceptional longevity. J Am Med Assoc 2003; 290: 2030-40

[20] Barzilai N, Gabriely I, Gabriely M, Iankowitz N, Sorkin JD. Offspring of centenarians have a favorable lipid profile. J Am Geriatr Soc 2001; 49: 76-9.

[21] Atzmon G, Rincon M, Rabizadeh P, Barzilai N. Biological evidence for inheritance of exceptional longevity. Mech Ageing Dev 2005; 126: 341-5.

[22] Li WW, Dammerman MM, Smith JD, et al. Common genetic variation in the promoter of the human apo CIII gene abolishes regulation by insulin and may contribute to hypertriglyceridemia. J Clin Invest 1995; 96: 2601-5

[23] Schechter CB, Barzilai N, Crandall JP, Atzmon G. Cholesteryl ester transfer protein (CETP) genotype and reduced CETP levels associated with decreased prevalence of hypertension. Mayo Clin Proc 2010; 85: 522-6

[24] Atzmon G, Rincon M, Schechter CB, et al. Lipoprotein genotype and conserved pathway for exceptional longevity in humans. PLoS Biol 2006; 4: e113.

[25] Terry DF, McCormick M, Andersen S, et al. Cardiovascular disease delay in centenarian offspring: role of heat shock proteins. Ann N Y Acad Sci 2004; 1019: 502-5.

[26] Rea IM, McNerlan S, Pockley AG. Serum heat shock protein and anti-heat shock protein antibody levels in aging. Exp Gerontol 2001; 36: 341-52.

[27] Jin X, Wang R, Xiao C, et al. Serum and lymphocyte levels of heat shock protein 70 in aging: a study in the normal Chinese population. Cell Stress Chaperones 2004; 9: 69-75.

[28] Terry DF, Wyszynski DF, Nolan VG, et al. Serum heat shock protein 70 level as a biomarker of exceptional longevity. Mech Ageing Dev 2006; 127: 862-8.

[29] Suh Y, Atzmon G, Cho MO, et al. Functionally significant insulinlike growth factor I receptor mutations in centenarians. Proc Natl Acad Sci USA 2008; 105: 3438-42.
[30] Claeysen S, Cochet M, Donneger R, Dumuis A, Bockaert J, Giannoni P. Alzheimer culprits: cellular crossroads and interplay. Cell Signal 2012; 24: 1831-40

[31] James BD, Wilson RS, Barnes LL, Bennett DA. Late-life social activity and cognitive decline in old age. J Int Neuropsychol Soc 2011; 17: 998-1005

[32] Lipton RB, Hirsch J, Katz MJ, et al. Exceptional parental longevity associated with lower risk of Alzheimer's disease and memory decline. J Am Geriatr Soc 2010; 58: 1043-9.

[33] Barral S, Cosentino S, Costa R, et al. Cognitive function in families with exceptional survival. Neurobiol Ageing 2012; 33: 619.e1-7

[34] Hagberg B, Samuelsson G. Survival after 100 years of age: a multivariate model of exceptional survival in Swedish centenarians. J Gerontol A Biol Sci Med Sci 2008; 63: 1219-26.

[35] Yates LB, Djoussé L, Kurth T, Buring JE, Gaziano JM. Exceptional longevity in men: modifiable factors associated with survival and function to age 90 years. Arch Intern Med 2008; 168: 284-90

[36] Franceschi C, Monti D, Sansoni P, Cossarizza A. The immunology of exceptional individuals: the lesson of centenarians. Immunol Today 1995a; 16: 12-6.

[37] Franceschi C, Monti D, Barbieri D, et al. Immunosenescence in humans: deterioration or remodelling? Int Rev Immunol 1995b; 12 57-74.

[38] Pawelec G, Akbar A, Caruso C, Solana R, Grubeck-Loebenstein B, Wikby A. Human immunosenescence: is it infectious? Immunol Rev 2005; 205: 257-68.

[39] Solana R, Pawelec G, Tarazona R. Aging and innate immunity. Immunity 2006; 24: 491-4.

[40] Sridharan A, Esposo M, Kaushal K, et al. Age-associated impaired plasmacytoid dendritic cell functions lead to decreased CD4 and CD8 T cell immunity. Age (Dordr) 2011; 33: 363-76

[41] Gupta S, Bi R, Su K, Yel L, Chiplunkar S, Gollapudi S. Characterization of naïve, memory and effector CD8+ T cells: effect of age Exp Gerontol 2004; 39: 545-50.

[42] Chong Y, Ikematsu H, Yamaji K, et al. CD27(+) (memory) B cell decrease and apoptosis-resistant-CD27(-) (naive) B cell increase in aged humans: implications for age-related peripheral B cell developmental disturbances. Int Immunol 2005; 17: 383-90.

[43] Colonna-Romano G, Bulati M, Aquino A, et al. A double-negative (IgD-CD27-) B cell population is increased in the peripheral blood of elderly people. Mech Ageing Develop 2009; 130: 681-90.

[44] Derhovanessian E, Maier AB, Beck R, et al.: Hallmark features of immunosenescence are absent in familial longevity. Immunol 2010 185:4618-24.

[45] Frasca D, Landin AM, Lechner SC, Ryan JG, et al. Aging downregulates the transcription factor E2A, activation-induced cytidinedeaminase, and Ig class switch in human B cells. J Immunol 2008; 15; 180: 5283-90.

[46] Shi Y, Yamazaki T, Okubo Y, Uehara Y, Sugane K, Agematsu K. Regulation of aged humoral immune defense against pneumococcal bacteria by IgM memory B cell. J Immunol 2005; 175: 3262-7.

[47] Listi` F, Candore G, Modica MA, et al. Study of serum immunoglobulin levels in elderly persons that provides new insights into B cell immunosenescence. Ann NY Acad Sci 2006; 1089: 487-95.

[48] Buffa S, Bulati M, Pellicanò M, et al. B cell immunosenescence: different features of naive and memory B cells in elderly. Biogerontol 2011; 12: 473-83.

[49] Bulati M, Buffa S, Candore G, et al. B cells and immunosenescence: a focus on IgG+IgD-CD27- (DN) B cells in aged humans. Ageing Res Rev 2011; 10: 274-84

[50] Mariotti S, Sansoni P, Barbesino G, et al. Thyroid and other organspecific auto antibodies in healthy centenarians. Lancet 1992; 339: 1506-8.

[51] Sansoni P, Cossarizza A, Brianti V, et al. Lymphocyte subsets and natural killer cell activity in healthy old people and centenarians. Blood 1993; 82: 2767-73.

[52] Cossarizza A, Ortolani C, Paganelli R, et al. CD45 isoforms expression on $\mathrm{CD} 4+$ and $\mathrm{CD} 8+\mathrm{T}$ cells throughout life, from newborns to centenarians: implications for T cell memory. Mech Ageing Dev 1996; 86:173-95.

[53] Candore G, Di Lorenzo G, Mansueto P, et al. Prevalence of organspecific and non organ-specific auto antibodies in healthy centenarians. Mech Ageing Dev 1997; 94: 183-90.

[54] Bagnara GP, Bonsi L, Strippoli P, et al. Hemopoiesis in healthy old people and centenarians: well-maintained responsiveness of CD34+ 
cells to hemopoietic growth factors and remodelling of cytokine network. J Gerontol A Biol Sci Med Sci 2000; 55: B61-6.

[55] Baggio G, Donazzan S, Monti D, et al. Lipoprotein(a) and lipoprotein profile in healthy centenarians: a reappraisal of vascular risk factors. FASEB J 1998; 12:433-7.

[56] Passeri G, Pini G, Troiano L, et al. Low vitamin D status, high bone turnover, and bone fractures in centenarians. J Clin Endocrinol Metab 2003; 88: 5109-15.

[57] Coppola R, Mari D, Lattuada A, Franceschi C. Von Willebrand factor in Italian centenarians. Haematologica 2003; 88: 39-43.

[58] Capri M, Salvioli S, Monti D, et al. Human longevity within an evolutionary perspective: the peculiar paradigm of a postreproductive genetics. Exp Gerontol 2008; 43: 53-60.

[59] Rea SL, Wu D, Cypser JR, Vaupel JW, Johnson TE. A stresssensitive reporter predicts longevity in isogenic populations of Caenorhabditiselegans. Nat Genet 2005; 37: 894-8.

[60] Cevenini E, Invidia L, Lescai F, et al. Human models of aging and longevity. Expert Opin Biol Ther 2008; 8: 1393-1405.

[61] Colonna-Romano G, Buffa S, Bulati M, et al. B cells compartment in centenarian offspring and old people. Curr Pharm Des 2010; 16: 604-8.

[62] Cancro MP, Hao Y, Scholz JL, et al. B cells and ageing: molecules and mechanisms. Trends Immunol 2009; 30: 313-8.

[63] Finch CE. The Biology of Aging (Academic Press, Burlington, MA), 2007.

[64] Oeseburg H, de Boer RA, van Gilst WH, van der Harst P. Telomere biology in healthy aging and disease. Pflugers Arch 2010; 459: 259-68.

[65] Zhu H, Belcher M, van der Harst P. Healthy aging and disease: role for telomere biology? Clin Sci (Lond) 2011; 120: 427-40.

[66] Atzmon G, Cho M, Cawthon RM, et al. Evolution in health and medicine Sackler colloquium: genetic variation in human telom- erase is associated with telomere length in Ashkenazi centenarians. Proc Natl Acad Sci USA 2010; 107 Suppl 1: 1710-7.

[67] Calado R, Young N. Telomeres in disease. F1000 Med Rep 2012; $4: 8$.

[68] Rose G, Passarino G, Scornaienchi V, et al. The mitochondrial DNA control region shows genetically correlated levels of heteroplasmyinleukocytes of centenarians and their offspring. BMC Genomics 2007; 8:293.

[69] Iwata N, Zhang J, Atzmon G, et al. Aging-related occurrence in Ashkenazi Jews of leukocyte heteroplasmicmt DNA mutation adjacent to replication origin frequently remodeled in Italian centenarians. Mitochondrion 2007; 7: 267-72.

[70] Gentilini D, Mari D, Castaldi D, et al. Role of epigenetics in human aging and longevity: genome-wide DNA methylation profile in centenarians and centenarians' offspring. Age (Dordr) 2012; Aug 25.

[71] Haendeler J, Dröse S, Büchner N, et al. Mitochondrial telomerase reverse transcriptase binds to and protects mitochondrial DNA and function from damage. Arterioscler Thromb Vasc Biol 2009; 29: 929-35.

[72] Sharma NK, Reyes A, Green P, et al. Human telomerase acts as ahTR-independent reverse transcriptase in mitochondria. Nucleic Acids Res 2012; 40: 712-25.

[73] Balistreri CR, Candore G, Accardi G, et al. Genetics of longevity: data from the studies on Sicilian centenarians. Immun Ageing 2012; 9:8

[74] Gentilini D, Castaldi D, Mari D, et al. Age-dependent skewing of $\mathrm{X}$ chromosome inactivation appears delayed in centenarians' offspring. Is there a role for allelic imbalance in healthy aging and longevity? Aging Cell 2012; 11: 277-83. 